\title{
Which Test of Thyroid Function?
}

\author{
C. W. H. HAVARD
}

British Medical fournal, 1974, 1, 553-556

Tests measuring the levels of thyroid hormone in the blood stream are now being used increasingly in the diagnosis of thyroid disorders. Correspondingly, less emphasis is placed on in vivo tests of thyroid uptake. The proliferation of in vitro tests of thyroid function has led to such confusion of nomenclature that many doctors do not know what they are asking for, much less the limitations of the panticular investigation in question. As tests of thyroid function are being sought with increasing frequency and with fewer indications, it is hardly surprising that many erroneous diagnoses are made.

Two important points need emphasizing to begin with: the first is that clinical criteria may be a better guide to the diagnosis of thyrotoxicosis and of hypothyroidism than any laboratory investigation, panticularly in the younger patient. A detailed medical history and a full physical examination are mandatory, and will lead to many fewer diagnostic errors than asking for a variety of tests after a few hasty observations in the clinic. The second point is that doctors tend to have a naive faith in the validity of laboratory reponts. Laboratory workers are human and are subject to the same errors as are clinicians; furthermore, errors may also be contributed by the methods used. Even when investigations are carried out in the best laboratories values outside the normal range occur in at least $5 \%$ of euthyroid people. In addition, the tests themselves are subject to limitations, which are often not appreciated by those asking for them. Laboratory tests are liable to interference by many factors unrelated to the thyroid gland and are just as subject to misinterpretation as the clinical findings.

Endocrine Unit, Royal Free Hospital, London WC1X 8LF C. W. H. HAVARD, D.M., F.R.C.P., Physician in Charge
While most clinicians are aware that iodine contaminationwhether taken in the form of a drug such as clioquinol (EnteroVioform) or as a result of radio-opaque contrast media-will raise the protein-bound iodine level, it is less well appreciated that oestrogens and hence the contraceptive pill increase the level of thyroxine-binding globulin so that the concentrations of proteinbound iodine (PBI) and the serum thyroxine (T-4) will be raised when the patient is euthyroid. ${ }^{2}$ Even less well appreciated is that thyrotoxicosis may be due to excess production of tri-iodothyronine ( $T-3)$ without any appreciable increase in thyroxine $(T-4)$ and so the conventional tests (which measure thyroxine) will fail to confirm an accurate clinical diagnosis of hyperthyroidism. ${ }^{3}$ At the other end of the scale, when hypothyroidism develops there may be a sequential failure of thyroxine production preceding a failure of the gland to produce $T-3.45$ Hence results of the conventional tests (PBI and serum T-4) may be low when the patient is euthyroid as a result of adequate T-3 production-a condition first reported in treated thyrotoxic patients ${ }^{6}$ but subsequently in iodine deficiency ${ }^{7}$ and in autoimmune thyroiditis.

\section{Physiology}

It is useful to review the normal physiology of thyroid hormone synthesis and transpont to understand the limitations of in vitro tests. The average British diet contains $100 \mu \mathrm{g}$ of iodide per day. This is absorbed from the gut into the inorganic iodide pool of the body. About one-third of the absorbed iodide is trapped by the thyroid gland and oxidized to iodine and the remainder is excreted in the urine. ${ }^{8}$

The iodine in the thyroid is organically bound to tyrosine to form mono-iodotyrosine and di-iodotyrosine. Two molecules of di-iodotyrosine are then combined to form thyroxine-or $\mathrm{T}-4$, as it has four iodine atoms. One molecule of mono-iodotyrosine is combined with one of di-iodotyrosine to form tri-iodothyronine, or T-3, as it has three iodine atoms. These two hormones are stored in the colloid of the thyroid gland as thyroglobulin and released by the proteolytic effect of pituitary thyrotrophic hormone (TSH) before being secreted into the blood. Pituitary TSH also controls the rate of trapping of circulating iodide by the thyroid gland and 
the enzymes which combine iodine with tyrosine and those which couple the iodotyrosines to form the two thyroid hormones. The release of TSH itself is under the control of a hypothalamic releasing factor, thytrophin-releasing hormone (TRH). TRH is a tripeptide which has been synthesized and is now available commercially. TRH does not release growth hormone, ACTH, or FSH but does increase the output of prolactin, probably as a result of similarities in the structure of the hypothalamic hormones concerned. ${ }^{10}$

\section{CIRCULATING HORMONES}

Both T-4 and T-3 circulate both as free hormone and bound to serum proteins, panticularly thyroxine-binding globulin (TBG)..$^{11-13}$ As with all hormones, only the minute amount of free hormone is biologically active: the much larger amount bound to protein is inert. Factors affecting the concentration of TBG will affect the level of protein-bound hormone even though free levels of hormone are unchanged. The commonest natural cause of increased TBG is normal pregnancy. Infective hepatitis may increase $\mathrm{TBG}^{14}$ and also drugs such as oestrogens ${ }^{2}$ and perphenazine. ${ }^{15}$ Some of the many factors which may reduce the capacity or circulating levels of TBG are listed in table $\mathrm{I}$.

TABLE I-Factors Reducing TBG

(1) Direct (a) Nephrosis48

(b) Acromegaly49

(c) Corticosteroids 50

(e) Androgens 42

(2) Indirect-Drugs binding to TBG

(b) Phenytoin54

The two thyroid hormones have differing affinities for TBG and this is why conventional in vitro thyroid function tests are more dependent on the circulating levels of $\mathrm{T}-4$. Thyroxine is $99.95 \%$ bound to protein ${ }^{16}$ while $T-3$ is only $99.5 \%$ bound. Thus the proportion of free $\mathrm{T}-3$ in the serum is 10 times that of free $\mathrm{T}-4 .^{3}$ The normal level of $\mathrm{T}-4$ in the serum is $5 \cdot 0-11.0 \mu \mathrm{g} / 100 \mathrm{ml}$ and that of $\mathrm{T}-3$ is $100-150 \mathrm{ng} / 100 \mathrm{ml} .{ }^{17}$ Thus the normal person has over 60 times as much circulating $T-4$ as $T-3$, and hence tests of protein-bound hormone will reflect $\mathrm{T}-4$ concentrations. Nevertheless, there is only six times as much free $T-4$ as there is free $T-3$ and, as $T-3$ is four times more potent than $T-4$, the metabolic contribution of $\mathrm{T}-3$ is nearly as great as that of $\mathrm{T}-4$.

Faotors altering the concentration of TBG will render the results of tests of protein-bound hormone misleading, for the increase in protein-bound hormone will not be accompanied by any increase in the free hormone level. The interpretation of tests that measure the circulating level of $T-4$ or $T-3$ depend therefore on a knowledge of the concentration of thyroxine-binding globulin and the extent to which the binding sites are occupied. Funthermore, anything which alters the normal ratio of $T-4$ to $T-3$ (table II) production will confuse the results of conventional investigations of thyroid funotionas changes in T-3 production will not be appreciably reflected by these tests.

TABLE II-Causes of Discrepancy between Serum Thyroxine and true Thyroid Status

(1) Change in serum concentration of TBG

(2) Drugs binding to TBG

(3) Conditions altering the ratio of $T-3$ to $T-4$

(a) Iodine deficiency

(b) Patients treated with thyroxine

(c) Patients treated with 1311

(d) T-3 thyrotoxicosis

FACTORS AFFECTING RELATIVE PRODUCTION OF T-4 AND T-3

The conditions favouring T-3 pnoduction have not been fully defined. Undoubtedly, however, iodine deficiency is a major factor. ${ }^{38-20}$ This is teleologically sound since $T-3$ has four times the metabolic activity of T-4 while using only $75 \%$ as much iodine.

About a six-fold increase in hormonal effect for the same amount of iodine can thus be achieved by a change from T-4 to T-3 production and this would obviously be advantageous in conditions of iodine deficiency. In hyperthyroidism the amounts of both hormones are usually increased. ${ }^{21}$ Though there is a preferential increase in T-3 production, its concentration does not usually equal that of $\mathrm{T}-4 .^{22}$ Clinical thyrotoxicosis may occur in patients with normal $T-4$ production and an increase in that of $T-3$, a disorder called T-3 thyrotoxicosis. ${ }^{3}$ It is not uncommon and the incidence may reach $10 \%$ in regions of iodine deficiency. ${ }^{23}$

Hence obviously there is a real need to measure the serum concentrations of $\mathrm{T}-3$.

\section{In Vitro Tests}

\section{PROTEIN-BOUND IODINE (PBI)}

Measurement of PBI has dominated in vitro tests of thyroid funotion for over 20 years. ${ }^{24}$ It is cheap, has a high degree of reproducibility, and can be automated. Its major drawback is the lack of specificity in that it measures non-hormonal forms of iodine in the blood. The iodine contamination of the environment is increasing steadily and a recent report from Edinburgh $^{25}$ suggested that $48 \%$ of a healthy euthyroid population had a spuriously raised PBI level. Possibly this is due to the fact that with greater use of laboratory facilities by general practitioners more patients are being referred to the endocrine clinics on account of a raised PBI. Our experience in London gives much greater reliability to the PBI. Indeed, when patients on the contraceptive pill are excluded, only $2 \%$ of a hospital population have falsely high PBI concentrations. ${ }^{26}$

Iodine is a constituent of health foods such as kelp. Iodine compounds are used in cosmetics, and as tetraiodofluorescein as a colouring material for many drugs and foods. ${ }^{27}$ The commonly prescribed intestinal antiseptic clioquinol (EnteroVioform) contains large quantities of iodine as does the amoebicide Diodoquin (di-iodohyroxyquinoline) and iodine is a constituent of many expectorants. If an autoanalyser is being used to determine the PBI the contamination produced by such drugs may be sufficient to invalidate the results of the whole run. The use of iodine-containing contrast media in radiology increases steadily. While the jodine of contrast media for an intravenous pyelogram may be excreted within two weeks, that used for a cholecystogram may persist for a month or more and the contamination resulting from bronchography or myelography may last for many years. Some radio-opaque intravenous cannul e contain iodine so that blood samples withdrawn through them will be contaminated.

All these facts, together with the advent of a specific assay for thyroxine by saturation analysis, means that there has been a swing away from the use of PBI estimations. Neventheless, it is probably still the most commonly used in vitro test of thyroid function in Britain, and when using it the risk of contamination must always be considered. The PBI also has the disadvantage that it does not differentiate hypenthyroidism from raised levels of thyroxine-binding protein. Nor can it differentiate between hypothyroidism and a reduction in available TBG. The available TBG may be reduced without any total reduction, because drugs such as phenytoin and salicylates are bound to the same plasma proteins as T-4 and so reduce the sites available to bind thyroxine.

The PBI test has a special use in thyroiditis, as the presence of iodoproteins released from the damaged gland can be detected in the serum: these iodoproteins are not T-4 so that measuring the serum levels of thyroxine will not detect them. 


\section{SERUM THYROXINE}

Most methods of measuring serum T-4 use the principle of competitive protein binding. ${ }^{28}$

If a small quantity of labelled $\mathrm{T}-4$ is added to a solution of TBG the proportion of T -4 which binds to protein can be determined. As more unlabelled T-4 is added to the system the proportion of labelled $\mathrm{T}-4$ bound to protein decreases. This added unlabelled T-4 can either be a known concentration and used to calibrate the system or T -4 derived from a test serum. To determine the fraction of $T-4$ bound to protein the bound $T-4$ must be separated from the free $T-4$. This is done by adding a secondary binder such as a resin or Sephadex. This competitive binding analysis has a precision comparable to that of the PBI test, ${ }^{29}$ and has been adapted for use as commercial kits, of which there are at least six currently available.

As it measures total T-4, the test does not differentiate between hyperthyroidism and raised levels of thyroxine-binding globulin or between hypothyroidism and reduced levels of available TBG, whether this is due to a total reduction or merely a reduction in available sites because of drugs bound to the same proteins. The normal range may vary slightly from laboratory to laboratory. Though the serum T-4 overcomes the problems of iodine contamination it does not overcome the problem of changes in TBG concentration produced by the ever-increasing use of oral contraceptives and other drugs. Nor does it give any indication of the level of T-3 in the serum.

\section{T-3 RESIN UPTAKE}

The $\mathrm{T}-3$ resin uptake is an indirect measure of the unoccupied thyroxine-binding protein sites available in the patient's serum. It does not give any information about the total serum $\mathrm{T}-3$ levels. It is unaffected by iodine contamination.

The principle of the test is based on the partition of added labelled T-3 between the binding sites of TBG on the one hand and a secondary binder, usually a resin, on the other. ${ }^{30} 31$ In more recent adaptations of this test Sephadex has replaced the resin as the secondary binder. TBG has a greater affinity for $T-4$ than for $T-3$ so that added $T-3$ will not actually displace $T-4$ from its binding to protein. In hyperthyroidism there will be fewer unoccupied binding sites on the serum proteins and hence the resin uptake will be increased. Conversely in hypothyroidism there will be an increase in available binding sites on the serum proteins as the total thyroxine is reduced. Hence the uptake by the resin will be reduced.

In patients on the contraceptive pill, though the total $T-4$ is increased, there is a greater increase in the TBG and hence the available binding sites on the serum proteins. The resin uptake will therefore be reduced. In pregnancy or in patients on the pill the serum T-4 will move into the hyperthyroid range, and the resin uptake will move into the hypothyroid range. The converse will occur if the level of TBG is reduced. The results may be expressed as a percentage uptake by the resin or as the thyrobinding capacity.

\section{FREE THYROXINE INDEX}

It has already been mentioned that when there is an alteration in the TBG the serum thyroxine levels and the T-3 resin uptake move in opposite directions. Thus in patients with an increase in TBG the serum thyroxine rises into the hyperthyroid range and the T-3 resin uptake moves into the hypothynoid range. A mathematical combination of serum thyroxine (or PBI) and T-3 resin uptake has been derived which gives normal values in euthyroid patients with abnormal levels of TBG. This combination of tests is called the free thyroxine factor $^{32}$ or free thyroxine index ${ }^{33}$ and correlates closely with the level of free thyroxine in the serum and reflects accurately the thyroid status of the individual..$^{34-36}$

Two new tests, the "effective thyroxine ratio" (ETR) $)^{37}$ and the "normalized thyroxine ratio (NTR) have recently become available and give similar information in a single test. Normalized T-4 tests promise to be useful screening tests of thyroid funotion and will be especially valuable if they can be automated.

\section{SERUM T-3}

With the production of specific antisera to $\mathrm{T}-3$ it is now possible to measure the small quantities of circulating T-3 by immunoassay..$^{30}$ There are several problems due to interference with the assay by endogenous TBG, and so at the moment this test is undertaken only in research centres. Nevertheless, the test is potentially suitable for use as a routine diagnostic test of thyroid function and in view of the importance of having some knowledge of circulating levels of $\mathrm{T}-3$ it will undoubtedly become more generally available.

\section{SERUM FREE THYROXINE}

Non-protein-bound or free thyroxine can be measured by a variety of techniques, none of which is suitable for routine use. Dialysis across a semipermeable membrane will separate the free T-4 from the bound T-4 and enable the propontion of free thyroxine to be determined. ${ }^{40}$ With a knowledge of the total serum T-4 level it is possible to calculate an absolute level of free hormone. The method is time-consuming and requires the use of isotopes. An indirect way of determining the free hormone level in the serum is to measure the urinary excretion of T-4. ${ }^{41}$ Similarly the urinary $T-3$ level offers an indirect means of estimating circulating levels of free $\mathrm{T}-3 . .^{22}$ These methods require the collection of timed specimens of urine and so have considerable disadvantages.

\section{SERUM TSH}

The serum concentration of TSH is measured by immunoassay. ${ }^{43-45}$

A mixture of unlabelled TSH and TSH labelled with a radioactive isotope is incubated for several days with a specific antiserum. Both the labelled and unlabelled TSH compete for binding sites on the antibody and at the end of this time a mixture of unlabelled TSH-antibody complex and labelled TSH-antibody complex is obtained. This mixture is precipitated using a second antibody and the amount of labelled TSH-antibody complex is counted. If there was little unlabelled TSH in the original sample there will be much labelled complex, and conversely if there was much unlabelled TSH there will be little labelled complex. By using a series of different known concentrations of unlabelled TSH and recording the amounts of labelled complex it is possible to contsruct a standard curve which can be used to estimate unknown samples.

The normal serum TSH level is low, being about $1 \mu \mathrm{U} / \mathrm{ml}$. It is raised in primary hypothyroidism and almost undetectable in hyperthyroidism. Because the normal levels of TSH are so low it is little help in the diagnosis of hyperthyroidism but it is a good test of hypothyroidism. The circulating TSH level is always raised in primary hypothyroidism, often to over $50 \mu \mathrm{U} / \mathrm{ml}$, but it is possible to find a raised level in a patient who is euthyroid. Indeed, raised TSH levels with normal circulating hormone levels will precede overt thyroid failure. ${ }^{21} 45$ Possibly such increased stimulation from the pituitary may prevent thyroid failure for many years.

\section{Dynamic Tests}

When the hypothalamic releasing factor TRH is given intravenously in a dose of $200 \mu \mathrm{g}$ the level of TSH in the serum rises from a basal level of about $1 \mu \mathrm{U} / \mathrm{ml}$ to a mean peak concentration of about $10 \mu \mathrm{U} / \mathrm{ml}$ at 20 minutes and returns to normal by 120 minutes. The response is usually greater in women than in men. In hypothyroidism there is an exaggerated rise of an already raised TSH level and in hyperthyroidism there is no response of a depressed TSH level."7 
The TRH test is a useful test of hypothyroidism when the rise in the basal TSH level is marginal and it is also useful in equivocal cases of hyperthyroidism. It is particularly relevant to the diagnosis of $T-3$ thyrotoxicosis if it is not possible to measure the circulating levels of $T-3$. The test will render redundant the $T-3$ suppression test, in which the autonomy of the thyroid gland was assessed by measuring the radioactive iodine uptake of the thyroid before and after five days of administered tri-iodothyronine. As with most tests, many drugs interfere with the results. Thyroxine, antithyroid drugs, conticosteroids, oestrogens, and levodopa will modify the TSH response to TRH. At present the use of TRH is restricted to those specialized centres that can monitor its effects-namely, those which can measure TSH by immunoassay. The main indications for the TRH test are in cases of mild hypothyroidism or hypenthyroidism when the diagnosis is in doubt, in hypopituitarism and in ophthalmic Graves's disease.

\section{Plan for Diagnosis}

In most cases of thyroid dysfunction confirmation of the diagnosis can be made by an estimation of the PBI or serum T -4 and a T-3 resin uptake. Calculation of a free thyroxine index should be made when there is any change in TBG and this is usually the result of pregnancy or of taking the contraceptive pill. An effective thyroxine ratio (ETR) or a normalized thyroxine ratio (NTR) gives similar information but has the distinot advantage of being a single test. When the serum $T-4$ and $T-3$ resin uptake confirm the clinical assessment there is no diagnostic problem and if a discrepancy can be accounted for by an abnormality in TBG funther investigation is not needed. When, however, the clinical appraisal and the initial test disagree funther investigation is required. If the patient is clinically thyrotoxic and the conventional tests are normal, the likely diagnosis is $\mathrm{T}-3$ thyrotoxicosis and the serum T-3 level should be estimated or a TRH test performed. If the patient is clinically euthyroid and the tests are in the hypenthyroid range, the clinical assessment should be reviewed and if the same clinical judgement is made no action should be taken. If there is any doubt a TRH test should be done.

If the patient is clinically hypothyroid but the results of the conventional tests are normal, the serum TSH should be estimated; if the serum TSH is not raised the patient is not suffering from primary hypothyroidism. The possibility of pituitary hypothyroidism has, however, not been excluded and an $x$-ray film of the pituitary fossa, an electrocandiogram, and a TRH test may help. If the patient is clinically euthyroid but the test results are in the hypothyroid range, the serum $\mathrm{T}-3$ level should be measured. The probability is that $T-4$ production is reduced but the patient is kept euthyroid by adequate production of T-3. A raised TSH in this condition does not prove the patient has primary hypothyroidism but a normal level excludes it.

\section{Conclusion}

All tests of thyroid funotion have their limitations. All are subject to interference by factors unrelated to the thyroid, especially drugs. All thynaid funotion tests are performed by human beings and are therefore subject to both human error and errors resulting from problems in methodology. The initial test of thyroid funotion should be the thorough, unhurried clinical assessment. A knowledge of the limitations of the various in vitro tests of thyroid function will lead to their more fruitful application and will reduce the diagnostic errors that so commonly result from their premature request.

\section{References}

1 Becker, D. V., and Hurley, J. R., Mayo Clinic Proceedings, 1972, 47, 835.

Hollander, C. S., Garcia, A. M., Sturgis, S. H., and Selenkow, H. A. New England fournal of Medicine, 1963, 269, 501 .

3 Hollander, C. S., and Shenkman, L., British fournal of Hospital Medicine, $1972,8,393$.

McConnon, J., Row, V. V., and Volpe, J., fournal of Endocrinology, 1971, $51,17$.

5 Wahner, J. W., and Gorman, C. A., New England fournal of Medicine, $1971,284,225$.

- Sterling, K., Bellabarba, D., Newman, E. S., and Brenner, M. A., fournal of Clinica! Investigation, 1969, 48, 1150 .

Delange, F., Camus, M., and Ermans, A. M., Fournal of Clinical Endo-

${ }^{8}$ crinology and Metabolism, 1972, 34, 891. Ekins, R. P., Clinical Endocrinology, 1973, 2, 193.

- Gharib, H., Wahner, H. W., and McConahey, W., Mayo Clinical Proceedings, 1972, 47, 175 .

10 Hall, R., British fournal of Hospital Medicine, 1973, 9, 109.

11 Woeber, K. A., and Ingbar, S. H., Fournal of Clinical Investigation, 1968, 47, 1710 .

12 Oppenheimer, J. H., New England fournal of Medicine, 1968, 278, 1153.

13 Hamada, S., Nakagawa, T., Mori, T., and Torizuka, K., Fournal of Clinical Endocrinology, 1970, 31, 166.

14 Vanotti, A., and Beraud, T., fournal of Clinical Endocrinology, 1959, 19, 466.

15 Oltman, J. E., and Friedman, S., fournal of the American Medical Association, $1963,185,726$.

16 Arango, G., Mayberry, W. E., Heckert, T. J., and Elveback, L. R., Mayo Clinical Proceedings, 1968, 43, 503.

17 Hoffenberg, R., Clinical Endocrinology, 1973, $2,75$.

18 Ivy, H. K., Wahner, H. W., and Gorman, C. A., Archives of Internal Medicine, 1971, 128, 529.

19 Hollander, C. S., et al., Lancet, 1971, 2, 731.

20 Greer, M. A., Mayo Clinic Proceedings, 1972, 47, 175.

21 Patel, Y. C., Burger, H. G., Clinical Endocrinology, 1973, 2, 339.

22 Benua, R. S., Dobyns, B. M., and Ninmer, A., fournal of Clinical Endocrinology, 1955, 15, 1367.

23 Hollander, C. S., et al., Lancet, 1972, 2, 1276.

24 Blackburn, C. M., and Power, M. H., fournal of Clinical Endocrinology and Metabolism, 1955, 15, 1379.

25 Toft, A. D., Seth, J., Kirkham, K. E., Marshall, A., and Irvine, W. J., Clinical Endocrionlogy, 1973, 2, 127.

26 Boss, A. M. B., et al, 1974, in press.

27 Bora, S. S., Radichevich, I., and Werner, S. C., fournal of Clinical Endocrinology and Metabolism, 1969, 29, 1269.

crinology and Metabolism, 1969, 29, 1269.
28 Murphy, B. P., fournal of Laboratory and Clinical Medicine, 1965, 66, 161.

29 Murphy, B. E. P., Pattee, C. J., and Gold, A., Fournal of Clinical Endocrinology, 1966, 26, 247.

30 Goolden, A. W. G., Gartside, J. M., Jackson, D. J., and Osorio, C., Lancet, 1962, $2,218$.

31 Wellby, M., and O'Halloran, M. W., Australasian Annals of Medicine, 1966, 15, 116.

82 Osorio, C., Jackson, D. J., Gartside, J. M., and Goolden, A. W. G., Clinical Science, 1961, 21, 355.

33 Clark, F., and Horn, D. B., fournal of Clinical Endocrinology, 1965, 25, 39.

ss Clark, F., and Horn, D. B., fournal of

35 Harvey, R. F., Lancet, 1971, 2, 230. $1971,67,793$.

36 Stein, R. B., and Price, L., Fournal of Clinical Endocrinology and Metabolism, 1972, 34, 225

37 Thorson, S C., Mincey, E. K., McIntosh, H. W., and Morrison, R. T., British Medical fournal, 1972, 2, 67. s8 Mitsuma, T., Nihei, N., Gershengorn, M. C., and Hollander, C. S.,

39 Chopra, I. J., Ho, R. S., and Lam, R., Fournal of Laboratory and Clinical Medicine, 1972, 80, 729.

40 Sterling, K., and Brenner, M. A., fournal of Clinical Investigation, 1966, 45, 153.

41 Chan, V., and Landon, J., Lancet, 1972, 1, 4.

42 Chan, V., Besser, G. M., Landon, J., and Ekins, R. P., Lancet, 1972, 2, 253

43 Utiger, R. D., Annals of Internal Medicine, 1971, 74, 627.

44 Hall, R., Amos, J., and Ormston, B. J., British Medical fournal, 1971, 1, 582 .

45 Irvine, W. J., Toft, A. D., Hunter, W. M., and Kirkham, K. E., Clinical Endocrinology, 1973, 2, 135.

46 Sterling, K., Brenner, M. A., Newman, E. S., Odell, W. D., and Bellabarba, D., fournal of Clinical Endocrinology and Metabolism, 1971, 33,

729.
47 Ormston, B. J., Garry, R., Cryer, R. J., Besser, G. M., and Hall, R.,

Lancet, 1971, 2, 10.
Robbins, J., Rall, J. E., and Peterman, M. L., Fournal of Clinical Investigation, 1957, 36, 1333 .

49 Roth, J., Glick, S. M., Cuatrecasar, P., and Hollander, C. S., Annals of Internal Medicine, 1967, 66, 760 .

50 Oppenheimer, J. H., and Werner, S. C., Fournal of Clinical Endocrinology, 1966, 26, 715.

51 Bellabarba, D., Inada, M., Varsano-Aharon, N., and Sterling, K., fournal of Clinical Endocrinology, 1968, 28, 1023.

52 Braverman, L. E., and Ingbar, S. H., Fournal of Clinical Endocrinology, $1967,27,389$.

53 Woeber, K. A., and Ingbar, S. H., fournal of Clinical Investigation, 1964, 43, 931 .

54 Chin, W., and Schussler, G. C., Fournal of Clinical Endocrinology, 1968, 28, 181 . 